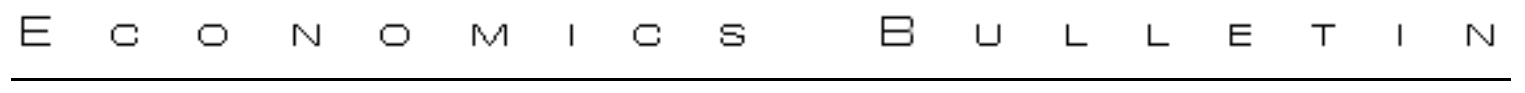

\title{
Trade Between Countries with Radically Different Preferences
}

\author{
Murray Kemp \\ Macquarie University
}

\author{
Koji Shimomura \\ Kobe University
}

\begin{abstract}
We examine the role of radical international differences in preferences in determining patterns of international trade, given that the trading countries share a common technology and identical factor endowment ratios. It is characteristic of our model that the equilibrium autarkic commodity price ratios are unique and negative and that there is a unique positive equilibrium free-trade price ratio, implying that the positive equilibrium free-trade price ratio is not bounded by the equilibrium autarkic price ratios. This finding contrasts sharply with the familiar Torrens-Ricardo and Heckscher-Ohlin propositions
\end{abstract}

Citation: Kemp, Murray and Koji Shimomura, (2005) "Trade Between Countries with Radically Different Preferences."

Economics Bulletin, Vol. 6, No. 18 pp. 1-9

Submitted: October 14, 2005. Accepted: October 31, 2005.

URL: http://www.economicsbulletin.com/2005/volume6/EB-05F10091A.pdf 


\section{Introduction}

In the standard Heckscher-Ohlin model of international trade, two trading countries share a common technology and common homothetic preferences but differ in their factor endowment ratios, which are therefore seen as determining the pattern of trade. In that model, the equilibrium free-trade commodity price ratio is non-negative and, since the preferences of each country are homothetic, bounded by the two equilibrium autarkic price ratios. These properties persist whether or not production is joint.

In the present paper we construct a model which differs from the standard model in important details: First, the preferences of the trading countries differ radically, in the sense that any commodity which yields satisfaction in one country yields dissatisfaction in the other; that is, any "good" in one country is a "bad" in the other country. Such a disparity in preferences might in turn be based on differences in climate or religious belief. Second, the two countries share a technology in which the final goods are jointly produced, and which allows each country to dispose of its "bad" by sacrificing some of its "good". (Under free trade the "bad" can also be disposed of by export.) Finally, there is a single primary factor of production, available in the same amount to each family. There is therefore no role for relative factor endowments in determining the pattern of trade.

It is characteristic of the model that, whether or not preferences are uniformly homothetic in each country, the equilibrium autarkic price ratios are unique and negative, and there is a unique positive equilibrium free-trade price ratio but possibly several negative equilibrium free-trade price ratios. It follows that the positive equilibrium free-trade price ratio is not bounded by the equilibrium autarkic price ratios. This finding contrasts sharply with the familiar Torrens-Ricardo proposition and with its Heckscher-Ohlin counterpart already cited. Even when there are multiple free-trade equilibria, with the additional free-trade price ratios negative, it remains true that no equilibrium free-trade price ratio is strictly bounded by the equilibrium autarkic price ratios. Moreover, it turns out that Marshallian local stability analysis, commonly preferred by trade theorists to the alternative Walrasian analysis, is inapplicable at free-trade equilibria with negative prices. On the other hand, the central proposition concerning trade gains (that, for each country, free trade is potentially preferred to no trade) remains intact.

The jointness of production suggests the possibility of undesirable by-products the disposal of which is costly. This in turn suggests the possibility of negative equilibrium prices, at least in a closed economy. What is surprising is that this latter possibility 
survives in a world economy in which no commodity is everywhere undesirable and in which the national economies are of approximately the same size.

\section{Autarkic Equilibria}

There are two countries, the home country and the foreign. In each country, two commodities, 1 and 2, are jointly produced by a single primary factor of production, labour, with one unit of labour yielding one unit of commodity 1 and a units of commodity 2 . The home country is endowed with $L$ units of labour, the foreign country with $L *$ units.

In the home country, households view commodity 1 as a good, commodity 2 as a bad; conversely in the foreign country.

Commodities 1 and 2 are disposable, at a cost. To dispose of one unit of commodity $i, b_{i j}>0$ units of commodity $j$ are needed $(i, j=1,2 ; i \neq j)$. However, for the time being it will be assumed that $b_{12}>a>1 / b_{21}$. Each country chooses the method of disposal appropriate to its preferences. Thus the relevant home production possibility locus is $A B$ in Figure 1(a), where the slope of $A B$ is $\max \left\{b_{12}, 1 / b_{21}\right\}$ and the length of $O A$ is proportional to $L$; and the relevant foreign production possibility locus is $A^{*} B^{*}$ in Figure $1(\mathrm{~b})$, where the slope of $A^{*} B^{*}$ is $\min \left\{b_{12}, 1 / b_{21}\right\}$ and the length of $O^{*} A^{*}$ is proportional to $L *$.

In Figure 1, II is a typical Scitovsky community indifference curve of the home country and $I^{*} I^{*}$ is a typical Scitovsky curve of the foreign country. Points $E$ and $E *$ represent the unique autarkic equilibria of the home and foreign countries, with negative equilibrium price ratios indicated by (minus) the slopes of $A B$ and $A^{*} B^{*}$. As indicated by the figure, each country chooses to rid itself of some but not all of its "bad".

\section{Free-Trade Equilibria}

Given the assumptions introduced in section 2, we can derive the home and foreign offer curves. These are displayed in Figures 2 and 3. Spinning Figure 3 through 180 and superimposing it on Figure 2, we obtain Figure 4. In the unique equilibrium marked by $E$, each country imports its preferred commodity, implying that the equilibrium terms of trade are positive. Since the autarkic price ratios are negative, they do not bound the world price ratio. Thus the familiar Torrens-Ricardo proposition has no counterpart in the present model. Moreover it can be verified that this is so even when preferences are uniformly homothetic in each trading country.

Nevertheless multiple equilibria are possible and can be obtained by varying the details of the common technology and of the country-specific preferences. However the additional equilibria always appear in the first and/or third quadrants, as in Figure 5. In those quadrants, one country exports both commodities, implying that the equilibrium world price ratio is negative. Thus it remains true that there is a unique positive price ratio 
and that it is not bounded by the two equilibrium autarkic price ratios. In fact it remains true that no equilibrium free-trade price ratio, positive or negative, is strictly bounded by the equilibrium autarkic price ratios.

In spite of the novel features of the world equilibria, each country gains from trade, in the weak sense that it is not harmed. A proof may be based on McKenzie's (1959, 1981) demonstration of the existence of a competitive general equilibrium, extended to accommodate two trading countries and one or more schemes of lump sum compensation. Thus if the free-trade equilibrium is represented by point $\mathrm{E}$ in Figure 4 or Figure 5 then each country is clearly better off than in autarky; and if the free-trade equilibrium is represented by $E_{1}, E_{2}, E_{3}$ or $E_{4}$ in Figure 5 then at least one country is better off (the other not worse off) than in autarky.

\section{Extensions}

In Sections 2 and 3 it was assumed that $b_{12}>a>1 / b_{21}$ so that, in Figure 1 , the slope of $O A$ is bounded by the slopes of $A B$ and $A^{*} B^{*}$. Other cases can be examined, with little change in conclusions. Thus if $a>b_{12}>1 / b_{21}$ then the straight and positively-sloped segment of the home offer curve $H H$ has slope a (not $b_{12}$ ); and if $b_{12}>1 / b_{21}>a$ then the straight and positively-sloped segment of the foreign offer curve $F F$ has slope a (not $\left.1 / b_{21}\right)$.

It has been assumed also that, in each country, aggregate preferences can be represented by a family of non-intersecting Scitovsky indifference curves. The assumption has been convenient, but only as an expository device. The reader may easily verify that all of our propositions, including those concerning the gains from trade, remain valid when the assumption is relaxed so that, in each country, preferences and labour endowments can differ from family to family while a radical international disparity of preferences is retained.

\section{Final Remark}

The analysis has been entirely static. Nothing has been said about the stability or instability of the equilibria; in particular, nothing has been said about the stability of the free-trade equilibria. In conclusion, we seek to make good this oversight. In the simple case depicted in Figure 4, there is a single equilibrium and the equilibrium price is positive. It is straightforward to confirm that the equilibrium is locally stable, both in the sense of Walras and in the sense of Marshall. In the case depicted in Figure 5, however, matters are more complicated. The unique equilibrium in quadrant 2 is characterized by a positive price ratio and local stability, both in the sense of Walras and in the sense of Marshall. The remaining equilibria, in Quadrants 1 and 3, are characterized by a negative price ratio and alternating Walrasian stability and instability, beginning with 
stability at $E_{1}$. However it is not possible to follow the Marshallian approach. For, when both commodities are exported by the same country, there is no single "supply price" associated with an equilibrium.

\section{References}

[1] McKenzie, L.W., "On the Existence of General Equilibrium for a Competitive Market," Econometrica 27 (1959), 54-71.

[2] McKenzie, L.W., "The Classical Theorem on Existence of Competitive Equilibrium," Econometrica 49 (1981), 819-841. 


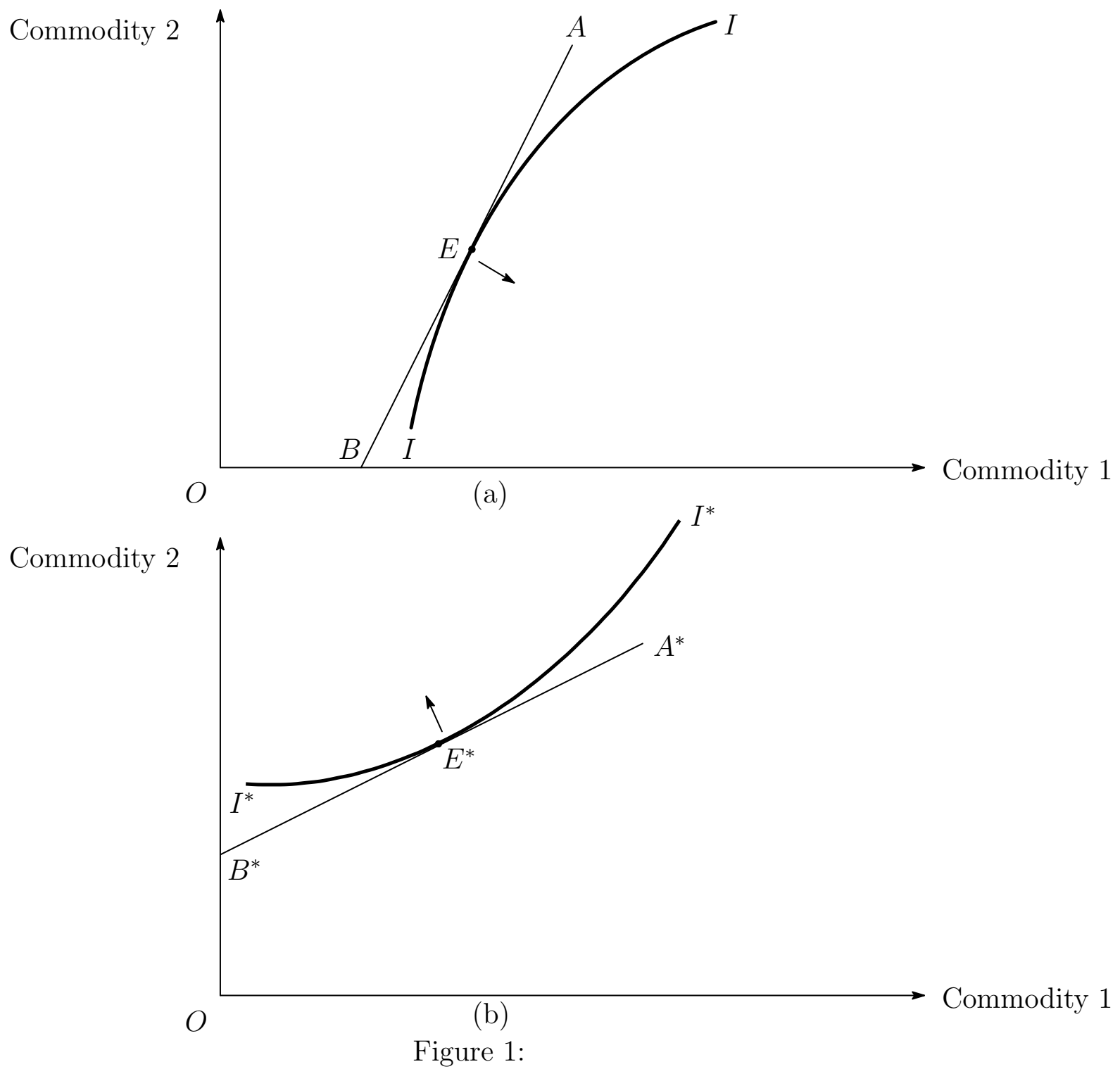

Figure 1: 


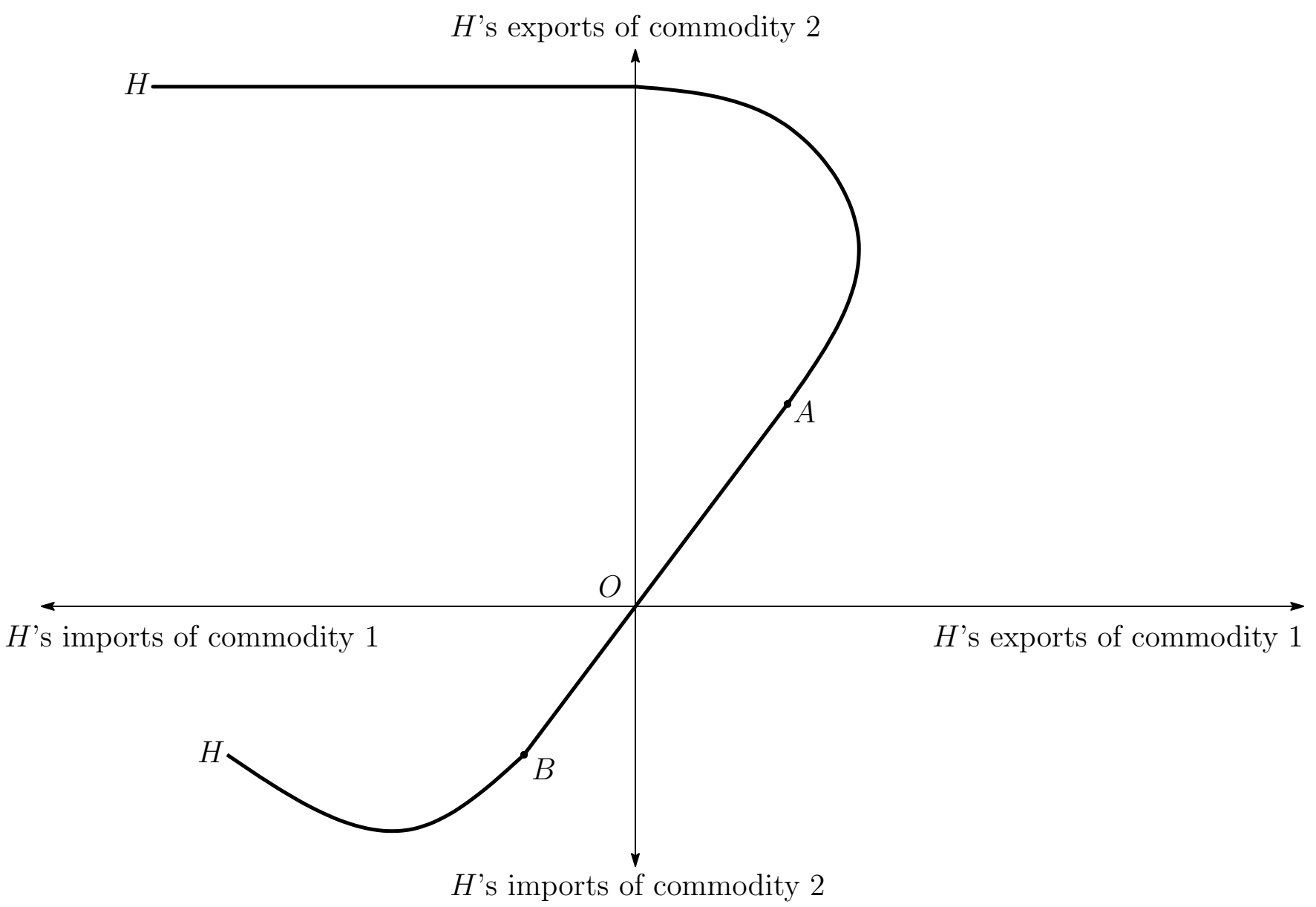

Figure 2: 


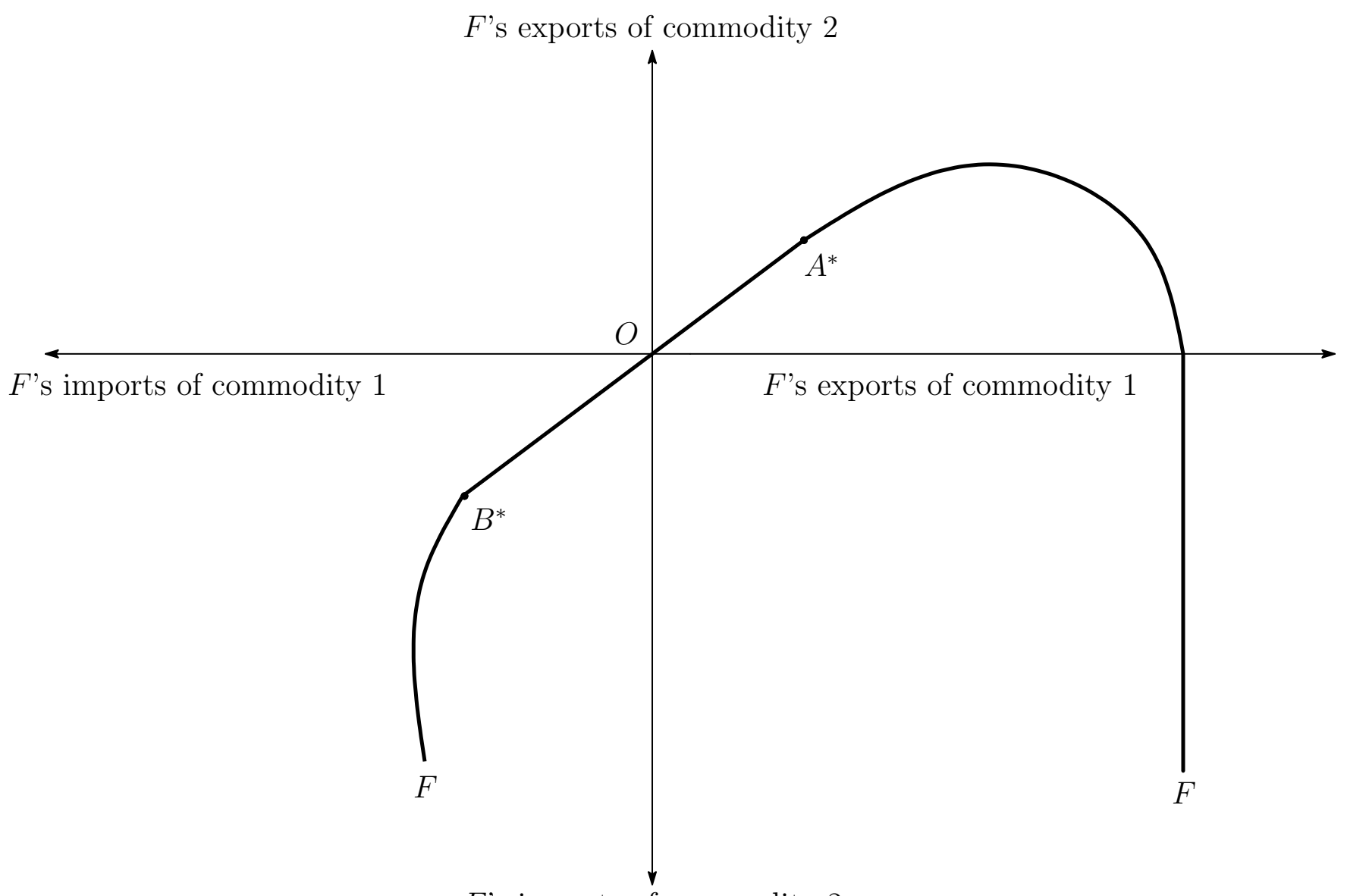

$F$ 's imports of commodity 2

Figure 3: 


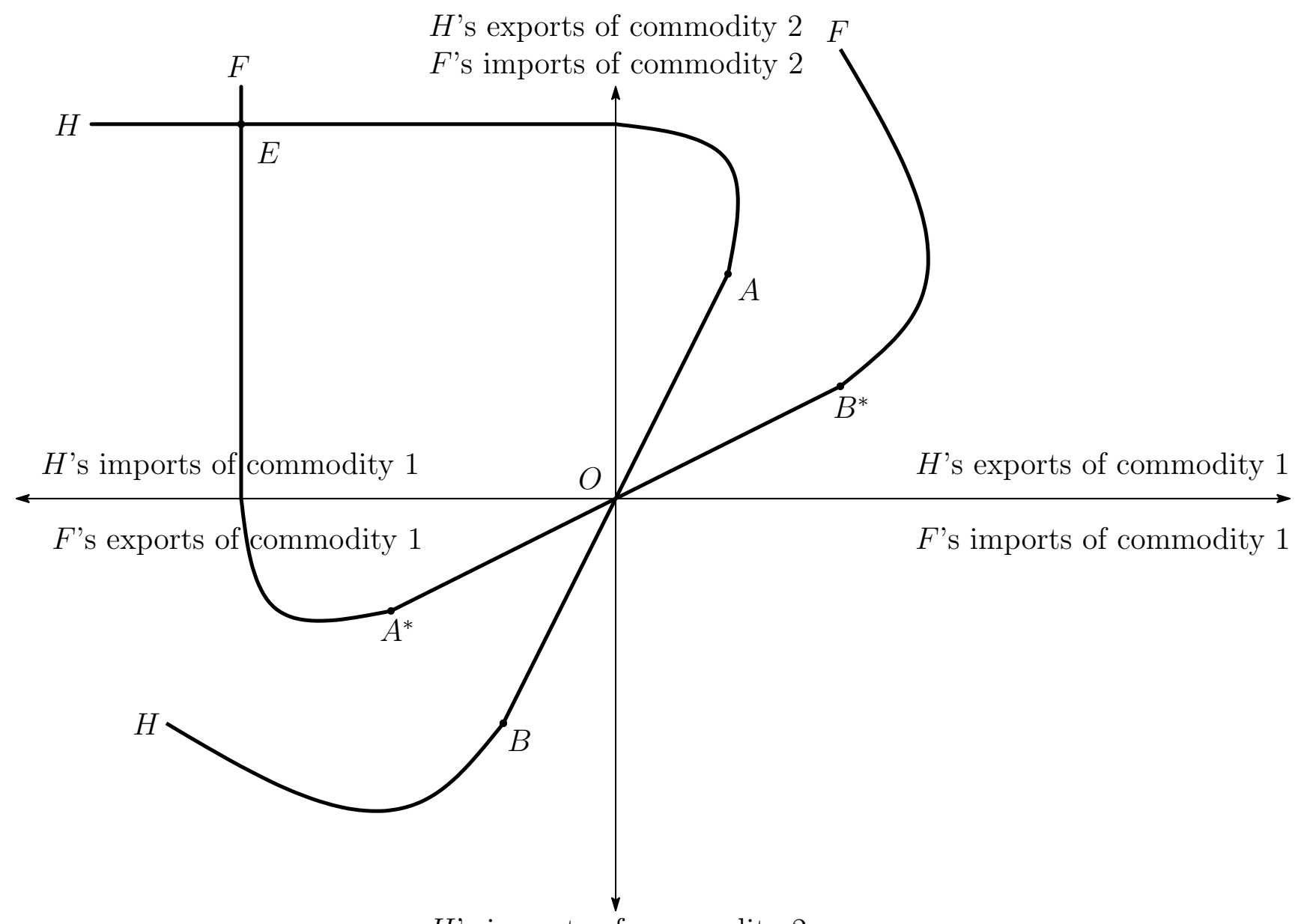

$H$ 's imports of commodity 2

$F$ 's exports of commodity 2

Figure 4: 


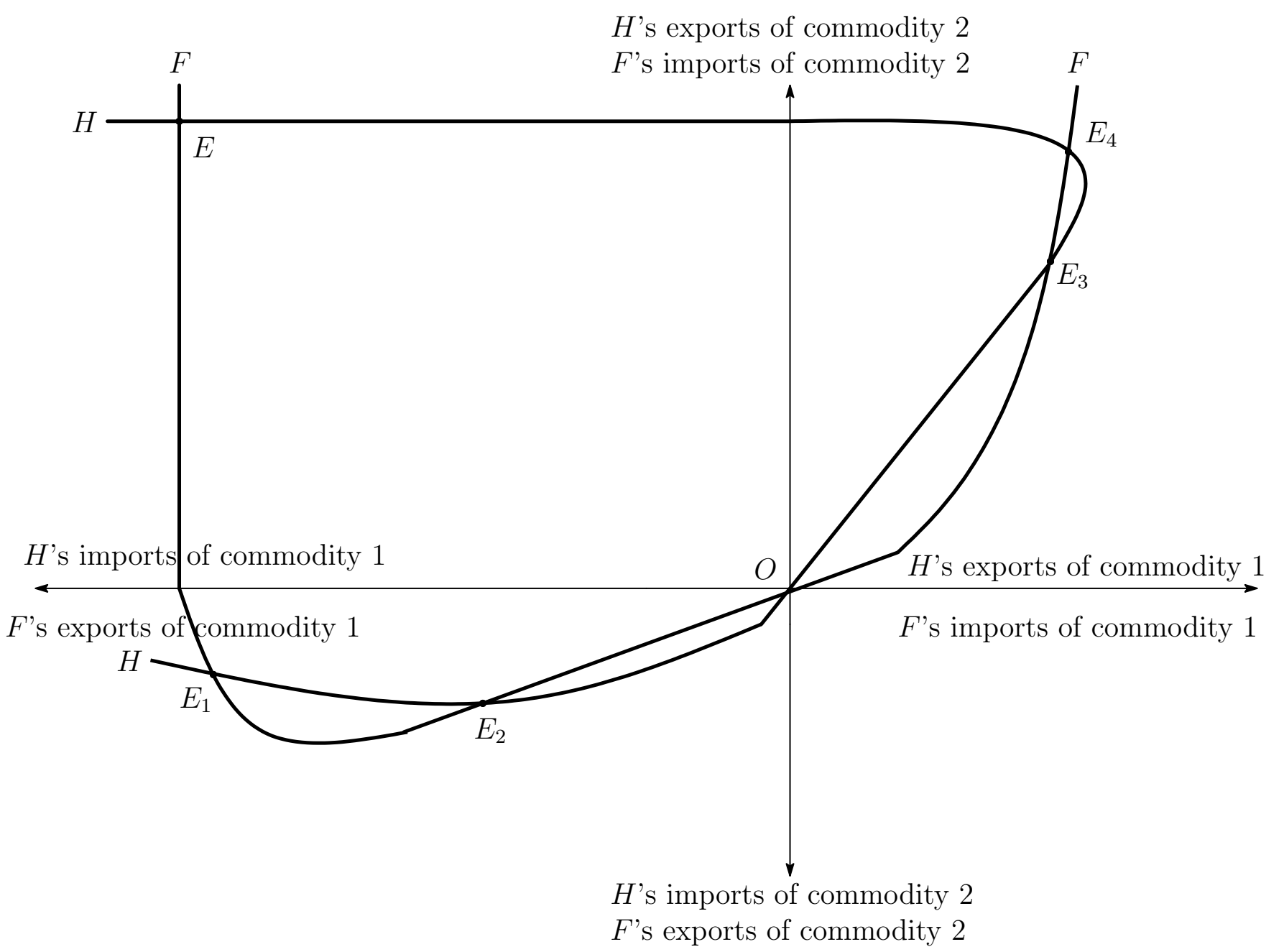

Figure 5: 